\title{
Analysis on the Culture behind Worship to Traditional Chinese Medicine Master Sun Simiao
}

\author{
Junli Yao, Yajun Li*
}

Shaanxi University of Traditional Chinese Medicine, Xianyang 712046, Shaanxi Province, China

\begin{abstract}
Worship to traditional Chinese medicine mater Sun Simiao is rooted in the traditional Chinese culture of Confucianism and Taoism, which attaches great importance to life and life in this world. The development and spread of Taoism is a platform for the promotion of traditional Chinese medicine master Sun Simiao. People's demand for medicine and health care is the basis of the folk culture behind worship to Sun Simiao. Medicine master culture of and worship to Sun Simiao's promoted people's healthy life and national prosperity, so it was widely recognized and spread.
\end{abstract}

Key words: Medicine master; Sun Simiao; Worship

Publication date: May, 2021; Publication online: 31 May, 2021

*Corresponding author: Yajun Li, liyajun@vip.126.com

\section{Introduction}

The worship to Sun Simiao is one of the most popular folk activities in the Chinese cultural circle. In its unique form, it integrates historical culture, medical culture, religious culture and folk culture. It has the characteristics of knowledge, education and entertainment. It embodies and spreads the great achievements of Chinese medical sages and sages, and radiates the brilliance of rationality and feelings of healthy culture ${ }^{[1]}$. A comprehensive and in-depth cultural analysis is of special value and significance to the construction and development of great health cause and the spread of traditional Chinese medicine culture.

\section{Origins of culture of worship to medicine master Sun Simiao}

2.1 The worship to Sun Simiao is rooted in Chinese traditional culture.

Sun Simiao's three schools of Confucianism, Taoism and Buddhism on Chinese traditional culture are mainly Taoism, with both cultivation and mastery. In Dayi Jingcheng, it is elaborated from the aspect of medical ethics, while in Qianjin Fang, it is embodied in the aspects of health preservation, treatment principles and medication. It fully shows that worship to traditional Chinese medicine master
Sun Simiao is completely rooted in the essence of Chinese traditional culture.

2.2 Worship to traditional Chinese medicine master Sun Simiao is a special phenomenon of "medicine master worship" on the basis of ancestor worship and God worship.

In the history of our country, the outstanding figures who have made great contributions to the happy life of the masses and the prosperity of the nation have been promoted to the humanized gods with Chinese characteristics and respected, according to the traditional correspondence between man and nature, the unity of man and nature, and the prominent ancestor worship, spirit worship, etc ${ }^{[2]}$. Worship to traditional Chinese medicine master Sun Simiao is a kind of medicine God worship evolved from Sun Simiao's legendary life and great contribution.

2.3 The worship to medicine master Sun Simiao's has a ideological basis which is philosophical view of attaching importance to life and earthly life.

This foundation comes from the positive philosophy of life and the idea of virtue and goodness held by the two traditional cultures of Confucianism and Taoism in China. Facing the suffering of existence and the crisis of spirit, whether people can save themselves or not is a great 
difference between eastern and Western cultures. The West prayed for God's salvation on the other side, while the ancient Chinese relied on self-salvation. Confucianism emphasizes the importance of body and life. It is said in the book of filial piety, the first chapter of the emperor's reign that "one's body is full of skin, one's parents dare not be hurt, and the beginning of filial piety.". Taoism and later Taoism pursue health preservation, longevity and immortality. In Ge Hong's baopuzi neipian, it is said that "my life is determined by me, not by the heaven, but also by the elixir. It will last for a hundred million years." in Sun Simiao's health preservation inscription, it is said that "life is not determined by life, but by self-cultivation.". If we can follow this principle, we can see the truth in the plain. The essence of this self-salvation under the Confucian and Taoist outlook on life can be described as the same source, different flow, and complementary.

\subsection{Sun Simiao has profound meaning as well as a fusion in depth and breadth.}

Sun Simiao has profound meaning as well as a fusion in depth and breadth. Therefore, in the preface of Qian Jin Yao Fang, he emphasizes that:" Human life is the most important thing." In the chapter of food administration of the book, the author first affirmed the relevant principles, saying that "the foundation of living is food.". Because, "those who don't know how to eat are not enough to survive.". In the chapter of nourishing human nature, it emphasizes the unity of health preservation, moral cultivation and good deeds. It holds that "the great Sutra of health preservation" lies in practicing good thoughts and "learning to become human nature". Because "the nature is good, all kinds of diseases inside and outside can not be known, and there is no reason for disasters.". If "virtue can't be conquered, if you take golden elixir and jade liquid, you can't prolong your life.". Sun Simiao thus summed up the "general purpose of health preservation", which is "the perfection of morality, the blessing without praying for goodness, and the self extension without seeking longevity". In qianjinyifang, there are many special chapters, which comprehensively and deeply describe the theories, principles and methods of practice, dietotherapy, health preservation, Bigu, retreat, tonic, and specific prescriptions, forming a complete health preservation system $^{[3]}$.

2.5 Sun Simiao's special emphasis on life and virtue is highly consistent with the traditional culture of Confucianism and Taoism as well as the people's

\section{desire for physical and mental health.}

Sun Simiao's legendary life and great contribution have a legendary influence on both the government and the people and continue to strengthen. Therefore, it quickly promotes the formation and continuous development of the king of medicine worship and the king of medicine culture.

\subsection{The development and spread of Taoism is a special platform for the promotion of worship to medicine master Sun Simiao's.}

In history, the formation and promotion of figure worship, religious and folk cultural factors, often far beyond the official. The formation and promotion of Sun Simiao's medicine King worship is just like this. Sun Simiao is not only a doctor, but also a Taoist. Sun Simiao made great efforts to save the world, devoted himself to medicine, and spread all over the country. There were many miraculous deeds to save the dying and heal the wounded. The broad masses of the people had long been worshiped as gods and worshiped the statues of temples. Therefore, Sun Simiao and all his works were naturally incorporated into the system of Taoism and promoted with the popularization of Taoism. It can be said that Sun Simiao's worship of the king of medicine laid a solid foundation in the Tang Dynasty. When Emperor Huizong of Song Dynasty arrived, Sun Simiao was granted the title of "Miaoying Zhenren" and was often called "Sun Zhenren" because of this, so he was finally determined and formed a brilliant and persistent tradition.In addition, Sun Simiao's legendary deeds are constantly deified, which makes the worship to medicine master Sun Simiao's widely spread $^{[4]}$

\subsection{The folk culture of medicine is the popular basis of worship to Sun Simiao's.}

In the folk pursuit of health, safety, happiness and longevity, Sun Simiao became the best candidate and belief in medicine. The local people built the medicine master temple, cave and Zhenren cave for him. They also built the statue in the image of medicine master in the Taoist temple. They regularly and irregularly went to sacrifice and offer sacrifices to pray for peace, blessing and disaster, and carried out various related activities, which formed a special folk culture of medicine and a lifestyle with rich health connotation. In terms of survival, folk culture and medicine and health have homology ${ }^{[5]}$. In terms of the pursuit of the highest happiness and the ultimate goal, folk culture and medicine and health have the same orientation. The study of folk culture has the characteristics and essence of group, 
inheritance, practicality and sustenance. Sun Simiao from a living person to be deified, so as to set the real king of medicine and extraordinary immortals as one of all, it can be said to provide an extremely rare ideal image for folk culture, so Sun Simiao king of medicine worship also has a very special symbolic significance and application value, under the influence of folk culture, from the beginning of both prosperity and prosperity, and then spread.

\section{Conclusion}

Worship psychology is the product of human self-consciousness, is one of the spiritual pillars of human life, can supplement the lack of real life, but also help to form a certain concept of life. Sun Simiao's superb medical skills are authentic, his medical works are rich, his medical methods are diverse, simple and practical, and his legends are widely spread. These make people gradually accumulate healthy psychological concepts and behavior patterns in worship.

In the worship activities passed down from generation to generation, the culture of and worship to medicine master can make people feel that their ancestors and gods are in front of and around them, and they are still protecting themselves and all living beings, so as to obtain the feeling, resonance and sustenance of emotion, spirit and soul. The whole life will be sublimated, and a high degree of cultural and psychological identity, group sense, group unity and social harmony will become more and more successful. These, because they are in line with many demands of the public, have far-reaching influence and spread widely for a long time. Undoubtedly, they are the natural development results and organic components of China's traditional social culture, which have had a positive effect from the beginning.

From the perspective of culture, we can draw the following conclusions: Chinese traditional culture is the cultural soil for the formation of the worship to the medicine master. Confucianism and Taoism attach importance to the philosophy of life and present life, which is the ideological basis for the occurrence of the worship to the medicine master. The development of Taoism is a platform for the promotion of the worship to the medicine master. The internal reason for the emergence of the worship to the medicine master is the homology of folk culture and medical culture, It is the life basis of the cultural and psychological accumulation of the king of medicine worship. The culture and worship to the medicine master have greatly promoted the healthy life of the people and the prosperity of the nation.

\section{References}

[1] Gou TL. Some information I know about Sun Simiao's research [C]. Proceedings of the first Chinese Medicine Culture Festival on Sun Simiao, October 2011, http://www.doc88.com/p-7025829248553.html.

[2] Qian Mu. Twelve Lectures on Chinese Culture [M]. Beijing: Kyushu Press, 2011.

[3] Niu WM, Liu ZB, Guo JH, Ma RL, Li LF. Sun Simiao. Overview of diet regimen [J]. Journal of Liaoning University of traditional Chinese medicine, 2019,21 (03): 28-30.

[4] Gan ZW. Commentary on Sun Simiao [M]. Nanjing: Nanjing University Press, 1995.

[5] Zhou XF, Wang ZP. Folk Culture and Traditional Chinese Medicine [M]. Beijing: China Press of Traditional Chinese Medicine, 2017.5. 